arousal seeking behaviour. ${ }^{20}$ Finally, volunteering parents were motivated by a desire to help others and contribute to medical research, but they were also searching for more information and better ways to help their own children, who were very young and had a distressing chronic illness.

As far as we can determine, there was no selection bias in the recruitment of the non-volunteering parents. The children were of similar age and severity of illness. The two groups of parents were also similar with regard to age, birth order, parity, and ethnic background. A higher proportion of the main decision makers in the volunteering group were women, and it is well known that women use drugs and health services more frequently than men. In addition, there were clear socioeconomic differences between the groups, and it is reasonably well established that social supports and behaviour that risks health are related to social state. The sample size was not large, and the data should therefore be interpreted with some caution. Nevertheless, the finding that volunteering parents were significantly more socially disadvantaged and emotionally vulnerable has important implications in the ethics of recruitment; vulnerable groups such as children, prisoners, students, and the mentally handicapped are generally excluded from clinical trials. The question arises whether current practice needs to be reviewed in the light of our finding that vulnerable parents may be volunteering their vulnerable children for clinical research.

We thank Dr David C Chant, group statistical adviser to the department of social sciences, University of Queensland, for help, advice, and guidance with analysing the data. This work was supported in part by a grant from the Mayne Bequest Fund, University of Queensland.

\section{Association of intravenous erythromycin and potentially fatal ventricular tachycardia with Q-T prolongation (torsades de pointes)} Ronald A Schoenenberger, Walter E Haefeli,
Philipp Weiss, Rudolf F Ritz

Department of Internal Medicine, Intensive Care Unit, University Hospital, 4031 Basle, Switzerland Ronald A Schoenenberger, $\mathrm{MD}$, senior registrar

Walter E Haefeli, MD, registrar

Philipp Weiss, MD, senior registrar

Rudolf F Ritz, MD, professor

Correspondence to: Dr Schoenenberger.

BrMed f 1990;300:1375-6
1 Spicker SF, Alon I, de Vries A, Engelhardt HT. The use of human beings in research: with special reference to clinical trials. Dordrecht: Kluwer Academic, 1988

2 Arras J, Hunt R. Ethical issues in modern medicine. Palo Alto: Mayfield Press, 1983.

3 Levine RJ. Ethics and regulations of clinical research. Baltimore: Urban and Schwarzenberg, 1986

4 Veatch RM. Medical ethics. Boston: Jones and Bartlett, 1989.

5 Barber B, Lally JJ, Makarushhka JL, Sullivan D. Research on human subjects: problems of social control in medical experimentation. New York: Russell Sage Foundation, 1973.

6 Cooke RA. Some notes on the subjects of biomedical and behavioural research. Report prepared for the President's commission for the study of ethical problems in Report prepared for the President's commission for the study of ethical problems in
medicine and biomedical and behavioural research. Washington DC: United medicine and biomedical and behavioural resed

7 Lasagna L, von Felsinger JM. The volunteer subject in research. Science 1954;120:359-61

8 Rosenthal R, Rosnow RL. The volunteer subject. New York: Wiley, 1975.

9 Kohn PM, Hunt RW, Davis CA, Cowles MP. Volunteering in principle, volunteering in fact and experience seeking. Psychol Record 1982;32 295-313.

10 Morokoff PJ. Volunteer bias in the psychophysiological study of female sexuality. Fournal of Sexual Research 1986;22:35-51.

11 Cowles M, Davis C. The subject matter of psychology: volunteers. Br $\mathcal{F}$ Soc Psychol 1987;26:97-102.

12 National Commission for the Protection of Human Subjects of Biomedical and Behavioural Research. Research involving children; report and recommendations: Washington DC: Department of Health, Education, and Welfare, tions: Washingt
1977. (77-0004.

13 Janofsky J, Starfield B. Assessment of risk in research on children. 7 Pediatr 1981;98:842-6.

14 Fost N. Parental control over children. F Pediatr 1983;103:571-2

15 Robinson R. Ethics committees and research in children. Br Med $\mathcal{F}$ 1987;294 $1243-4$

16 Coulter DL, Murrary TH, Cerreto MC. Practical ethics in pediatrics. Cur Probl Pediatr 1988;18:139-95.

17 Australian Bureau of Statistics. Census of population and housing: characteristics of persons and dwellings in local authority areas, statistical divisions and statistical districts, Queensland. Canberra: ABS, 1986.

18 SAS Institute. SAS, SAS/STAT. Guide for personal computers. 6th ed. Cary, North Carolina: SAS Institute, 1987.

19 Wilkonson L. Systat: the system for statistics. Evanston, Illinois: Systat Inc., 1988.

20 Schubert DSP. Arousal seeking as a motivation for volunteering: MMPI scores and central nervous system stimulant use as suggestive of a trait. Fournal of Projective Techniques and Personality Assessment, 1964;28:337-40.

(Accepted 20 March 1990)
Ventricular arrhythmias during treatment with erythromycin are a rare but important side effect.' We report a case of potentially lifethreatening ventricular arrhythmias associated with prolongation of the Q-T interval induced by erythromycin.

\section{Case report}

A 61 year old woman was admitted with fever, pneumonia, and severe respiratory distress (respiratory rate $40 / \mathrm{min}$, arterial oxygen pressure $7 \cdot 4 \mathrm{kPa}$ breathing 101 oxygen $/ \mathrm{min}$ ). She was maintained with phenprocoumon because of longstanding pulmonary hypertension secondary to pulmonary embolism. Examination disclosed tricuspid regurgitation; an enlarged, tender liver; pulse rate 108/min; and blood pressure $125 / 70 \mathrm{~mm} \mathrm{Hg}$. The electrocardiogram showed sinus tachycardia, right atrial hypertrophy, and a normal rate corrected Q-T interval $\left(\mathrm{Q}-\mathrm{T}_{\mathrm{c}} 410\right.$ $\mathrm{ms})$. Results of laboratory investigations were: sedimentation rate $64 \mathrm{~mm}$ in first hour; haemoglobin concentration $180 \mathrm{~g} / \mathrm{l}$; white cell count $37 \times 10^{9} / 1(75 \%$ band forms); plasma bilirubin concentration $99 \mu \mathrm{mol} / 1$ (normal <15.4); serum aspartate aminotransferase activity $95 \mathrm{U} / 1$ (normal 6-23). Plasma electrolyte concentrations, including potassium, sodium, calcium, and magnesium, were normal, as was the plasma creatinine concentration. Ceftriaxone ( $2 \mathrm{~g}$ daily) and erythromycin lactobionate $(1 \mathrm{~g}$ thrice daily infused in saline over 90 minutes) were started. During the fifth infusion of erythromycin pronounced prolongation of the Q- $T$ interval $\left(Q-T_{c} 550 \mathrm{~ms}\right)$, multiform ventricular extrasystoles, and an episode of non-sustained torsades de pointes occurred.

During the eighth and 10th infusions several electrocardiograms and rhythm strips were recorded, showing increasing $\mathrm{Q}-\mathrm{T}_{\mathrm{c}}$ intervals during infusion and a gradual return to normal over the subsequent five to six hours (figure). Coinciding with maximal prolongation of the Q-T $T_{c}$ interval again torsades de pointes occurred. Electrolyte and cardiac enzyme values remained normal and an electrocardiogram recorded shortly after the last episode of torsades de pointes showed no signs of myocardial ischaemia. During the periods of

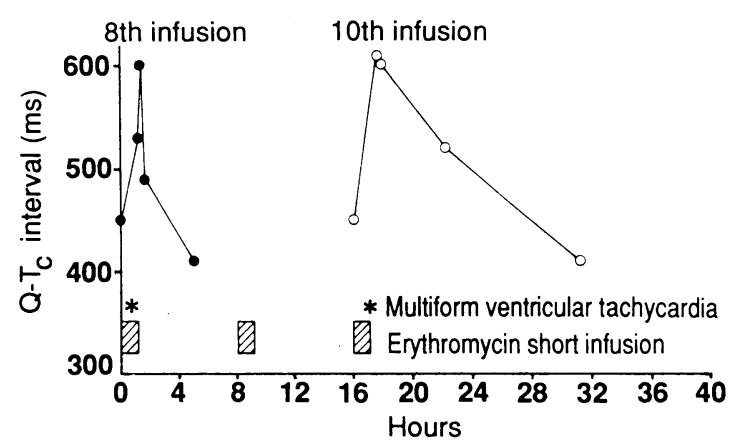

Time course of changes in $Q-T_{\text {c interval (rate corrected } Q-T \text { interval }}$ according to Bazett's formula) during two 90 minute infusions of erythromycin 
rhythm disorders no other drugs known to prolong the Q-T interval and induce torsades de pointes-for example, diuretics or antiarrhythmics-had been given. Antibiotic treatment was changed to ciprofloxacin. No further arrhythmia occurred and the patient was discharged three weeks later.

\section{Comment}

Ventricular arrhythmia associated with prolongation of the $Q-T_{c}$ interval is a well known side effect of several drugs. In our patient the close temporal relation of prolongation of the Q- $\mathrm{T}_{\mathrm{c}}$ interval and infusion of erythromycin with the maximum interval occurring at the end of the infusion and a gradual return to normal over the next few hours strongly suggested a direct dependence of the $\mathrm{Q}-\mathrm{T}_{\mathrm{c}}$ interval on the plasma concentrations of erythromycin. That we recorded this phenomenon during two separate drug infusions lends support to this suggestion. A possible association of erythromycin with ventricular arrhythmias has been reported. ${ }^{12}$ Prolongation of the Q-T interval was the common feature in all cases. Nevertheless, given the widespread use of erythromycin, the low rate of drug associated arrhythmias recognised is remarkable.

In our patient ventricular extrasystoles and torsades de pointes occurred only at the time when peak plasma concentrations would be expected and when the longest $\mathrm{Q}-\mathrm{T}_{\mathrm{c}}$ interval was seen. How erythromycin alters cardiac repolarisation is not clear, but a recent electrophysiological study has shown that erythromycin exerts a concentration dependent quinidine-like effect. ${ }^{3}$ Aside from the mode of administration leading to different peak plasma concentrations other factors must be considered. In patients with pre-existing prolongation of the Q-T interval-for example, in idiopathic long Q-T syndrome ${ }^{4}$-erythromycin may worsen the repolarisation abnormality and induce arrhythmias. As in other published cases ${ }^{2}$ our patient had a normal Q-T interval before being given the drug. Other factors such as alterations of erythromycin pharmacokinetics resulting in different individual susceptibility may be important. Both structural damage of liver tissue and cotreatment with other drugs competing for the same hepatic cytochrome (P450IIIA4) may impair hepatic drug clearance and lead to critically raised plasma concentrations of erythromycin. ${ }^{5}$ The hepatic dysfunction present in our patient may have been a main factor contributing to the erythromycin toxicity.

To minimise the danger of toxic plasma concentrations rapid injections of erythromycin should be avoided as recommended by the manufacturers. In patients at risk close $Q-T_{c}$ and rhythm monitoring may be advisable. In a patient with impaired hepatic drug metabolism or pre-existing cardiac disease a smaller dose or an alternative antibiotic should be considered.

1 McComb JM, Camphell NPS, Cleland J. Recurrent ventricular tachycardia associated with QT prolongation after mitral valve replacement and its association with intravenous administration of erythromycin. $A m \mathcal{f}$ (Cardiol 1984;54:922-3.

2 Guelon D, Bedock B, Chartier Ch, Haberer JP. QT prolongation and recurren "torsades de pointes" during erythromycin lactobionate infusion. "torsades de pointes"
Am f Cardiol 1986;58:666.

3 Ponsonnaille J, Citron B, Richard A, et al. An electrophysiological study of the arrhythmogenic effects of erythromycin. Arch.Mal Coeur 1988;81:1001-8.

4 Freedman RA, Anderson KP, Green LS, Mason JW. Effect of erythromycin on ventricular arrhythmias and ventricular repolarization in idiopathic long QT syndrome. Am f Cardiol 1987;59:168-9.

5 Kroboth PD, Brown A, Lyon JA, Kroboth FJ, Juhl RP. Pharmacokinetics of single-dose erythromycin in normal and alcoholic liver disease subjects. Antimicrob Agents Chemother 1982;21:135-40.

(Accepted 2.March 1990 )

\section{Prolonged recovery of renal function after prostatectomy for prostatic outflow obstruction}

\section{R R Ghose}

Singleton Hospital, Sketty, Swansea SA2 8QA R R Ghose, FRCP, consultant physician

Br.Med f 1990;300:1376-7

High pressure chronic retention from prostatic outflow obstruction presents with few urological symptoms, but the presence of late onset enuresis and a painless, palpable bladder, with hypertension or peripheral oedema, should suggest the diagnosis. ${ }^{1}$ Progressive renal failure is a feature of this condition, and prostatectomy is essential to relieve obstruction of the lower urinary tract. Prospective tests of renal function done up to one year after prostatectomy show that appreciable improvement may occur. ${ }^{2}$ Further recovery may, however, occur some years later and these observations form the basis of my report.

\section{Patients, methods, and results}

Three men, aged 48, 51, and 63, with typical features of high pressure chronic retention associated with prostatic outflow obstruction, were studied prospectively for between three and nine years after prostatectomy. 'They formed part of a larger series of six patients, one of whom had died of an unrelated cause and two had not yet been followed up for three years. ${ }^{2}$ All six patients showed a consistent improvement in renal function over a period of 12 months, with their mean glomerular filtration rate rising from $27 \mathrm{ml} / \mathrm{min} / 1.73 \mathrm{~m}^{2}$ to $56 \mathrm{ml} / \mathrm{min} / 1.73 \mathrm{~m}^{2}$ and their mean effective renal plasma flow rising from $88 \mathrm{ml} /$ $\min / 1.73 \mathrm{~m}^{2}$ to $221 \mathrm{ml} / \mathrm{min} / 1.73 \mathrm{~m}^{2}(\mathrm{p}<0.02$ for both values). Their mean filtration fraction was 0.30 preoperatively and $0 \cdot 25$ one year after prostatectomy.

All three patients were hypertensive at presentation, but two became permanently normotensive within days of prostatectomy. The third patient experienced resurgence of severe hypertension two months after prostatectomy requiring control with multiple antihypertensive drugs.

The figure shows the effective renal plasma flow and glomerular filtration rate for each patient before and after prostatectomy. ${ }^{3}$

Intravenous urography, renal tract ultrasonography, and gammacamera renography were performed before prostatectomy and at arbitrary intervals after for several years. Initial urography showed gross bilateral hydronephrosis and hydroureter in all three patients, which changed to normal appearances some years after prostatectomy. These findings were confirmed by ultrasonography.

The renographic findings were not diagnostic of obstructive nephropathy before prostatectomy, but they did show bilateral impairment of renal function with poor uptake of isotope. Nevertheless, when renal function had recovered a normal renogram pattern was seen.

\section{Comment}

Prognosis in high pressure chronic retention depends on the degree of renal damage at the time of presentation. No test can gauge whether irreversible pathological changes have occurred. Even when renal function is substantially impaired initially, the amount of recovery possible may be established only by surgical relief of the obstruction or by catheterisation 